\title{
A PERFOMANCE STUDY OF ANN AND ANFIS CONTROLLER FOR STATCOM IN dSPACE ENVIRONMENT
}

\author{
S. Arockia Edwin Xavier - P. Venkatesh - M. Saravanan *
}

\begin{abstract}
Reactive power compensation is an important issue in the control of electric power system. Reactive power from the source increases the transmission losses and reduces the power transmission capability of the transmission lines. Moreover, reactive power should not be transmitted through the transmission line to a longer distance. Hence Flexible AC Transmission Systems (FACTS) devices such as static compensator (STATCOM) unified power flow controller (UPFC) and static volt-ampere compensator (SVC) are used to alleviate these problems. In this paper, a voltage source converter (VSC) based STATCOM is developed with Artificial Neural Network Controller (ANNC) and Adaptive Neuro Fuzzy Inference System(ANFIS) controllers. The conventional PI controller has more tuning difficulties while the system parameter changes, whereas a trained neural network and ANFIS controllers requires less computation time. They have the ability to generalize and can interpolate in between the training data. The ANNC and ANFIS controllers designed were tested on a $75 \mathrm{~V}, 100 \mathrm{VA}$ STATCOM in real time environment via state-of-the-art of digital signal processor advanced control engineering (dSPACE) DS1104 board and it was found that ANFIS controller was producing better results than the ANNC.
\end{abstract}

K e y w o r d s: ANFIS, artifcial neural network, dSPACE DS1104, STATCOM, pulse width modulation

\section{INTRODUCTION}

The improvement in power semiconductor devices acts as a major factor for the increased importance of power electronics in future power system. A power electronic converter based high speed $360^{\circ}$ phase shifter can control power flow between two systems, regardless of frequency, voltage and impedance variations [1]. The operation of different FACTS devices such as SSR damper, Phase angle regulator, Static condenser, STATCOM and Thyristor Controlled Series Capacitor (TCSC) were discussed and the role of the above devices in the future power system was also studied [2]. STATCOM is designed based on VSC topology and sinusoidal PWM technique is used to control the amplitude and phase of converter output voltage. TMS320F240 DSP based \pm 3 KVAR rating STATCOM is reported for compensating lagging and leading power factor loads [3]. A high power self commutating inverter based static condenser (STATCON) is developed and two types of modules for voltage and phase angle control are explained from the basic fundamental equations and transient response curve is given [4]. Experimental $\pm 5 \mathrm{KVAR}$ STATCOM model using DSP, with sinusoidal PWM control having the carrier frequency of $2.8 \mathrm{KHz}$ is developed. PI controller is designed using $d q$ frame linearized model and system parameters variations such as, variation of load of $2.3 \mathrm{KW}$ and closed loop dynamics are observed in $30 \mathrm{KVA}$ and 110v system [5]. The mathematical model of STATCOM based on space vector theory and also the behavior of STATCOM for voltage regulation with simple PI controller is simulated with ATP-EMTP. The value of the capacitor is changed in steps and the frequency of oscillations for various steps is studied. Magnitude of reactive current injected/absorbed by STATCOM is linearly proportional to phase angle. It is also observed that the bus voltage is recovered within three cycles after the load disturbance is given [6]. A discrete linear time varying model of the three-phase VSC is developed and this model is employed to determine the steady-state operating characteristics of a VSC in closed loop form, as a function of converter duty cycle and phase angle [7]. A schematic for the reconfigurable FACTS system is designed and a real time control for the above FACTS system is also developed. The state models for STATCOM, Static Synchronous Series Compensator (SSSC) and Unified Power Flow Controller (UPFC) are designed using $d q$ co-ordinates. A PI based controller is developed for the above models. Simulations and experimental results are compared and verified [8]. A novel switching function model for the STATCOM, SSSC and the UPFC based on a multi-pulse voltage-sourced converter topology had been developed [9]. Recent advances in computing hardware, sophisticated power system, and component modeling techniques are significantly increasing the application of real time digital simulation in power system industry. Real time operation implies that an event in the system which lasts for one second is simulated on the simulator exactly in one second. The performance of the STATCOM controller is validated in real time using a detailed model of the power system implemented using Linux PC-based, multi-processor technology [10]. In the Hardware in loop (HIL) simulation, an actual controller for STATCOM is connected in closed loop with a realtime virtual plant model. The challenges of real-time simulation such as, achieving a very small time step with a power system containing multi-switch devices, preventing the non-characteristic harmonics, and achieving the simulator scalability by distributing the simulation execution over several processors had been overcome using PC based RT-LAB simulator [11]. A VSC based STATCOM is modelled using MATLAB simulink tool boxes. A real time hardware for STATCOM is developed and us-

* EEE Department, Thiagarajar College of Engineering, Madurai 625015, Tamilnadu, India, Saexeee@tce.edu 


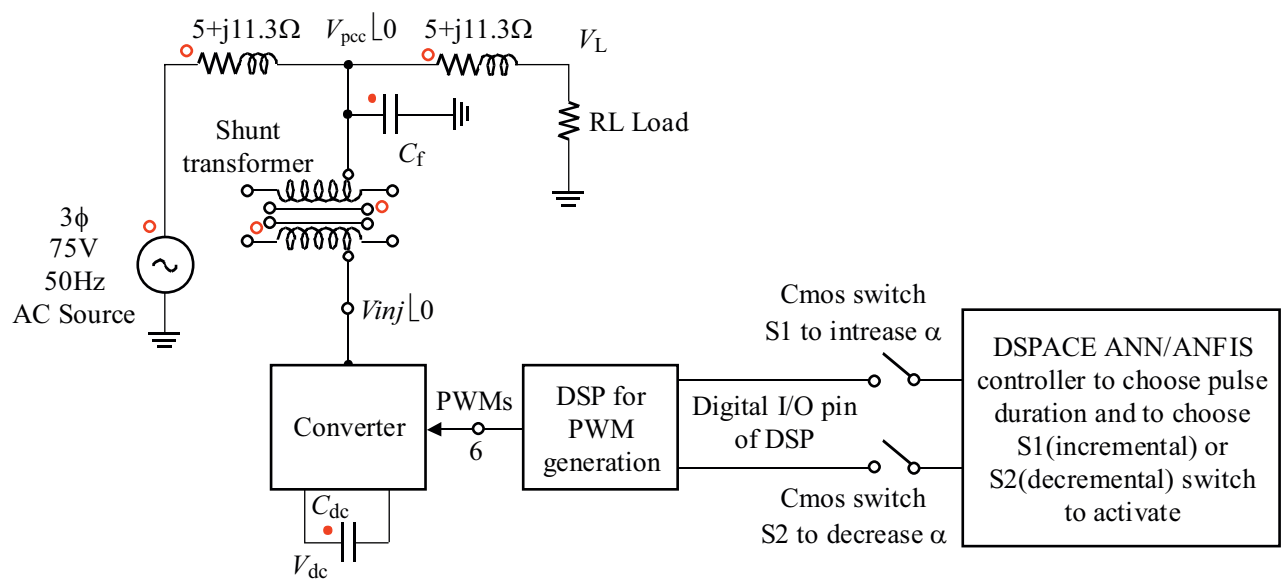

Fig. 1. The calculated flux linkage characteristics

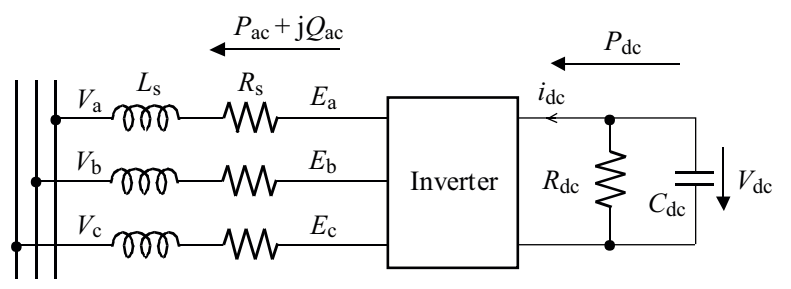

Fig. 2. Equivalent circuit model of STATCOM

ing dSPACE software and DSP controller, the modulation index and phase angle are adjusted to get the required reactive power compensation. Simulation and experimental results are compared [12]. A neuro fuzzy controller is designed for STATCOM in such a way that it improves the damping of the rotor speed deviations of its neighboring generator [13]. A coordination controller is developed to minimize the number of tap-changes in the transformer while maintaining an acceptable STATCOM output voltage magnitude at the substation bus [14].

In order to fully understand how to effectively incorporate FACTS devices in the existing power system, a hardware prototype for verification is necessary in addition to software simulation. A PI controller is implemented in a neural network called ANNC and AFNIS were presented in this paper. The ANNC and ANFIS were trained in such a way to reduce the steady state error, peak overshoot and settling time. The STATCOM is simulated with the trained neural network and ANFIS to achieve the desired performance using matlab/simulink. The performance of the above STATCOM is experimentally verified with ANNC and ANFIS controller. The reference value of point of common coupling voltage $\left(\mathrm{V}_{\mathrm{pcc}}\right)$ is varied while the real time simulation is running and then the ability of STATCOM to track the reference $\mathrm{V}_{\mathrm{pcc}}\left(\mathrm{V}_{\mathrm{pccref}}\right)$ is observed.

In this paper, real time simulation of a power system with STATCOM under load disturbance is done with ANNC and ANFIS controller using a practical hardware of $\pm 3 \mathrm{KVAR}, 75 \mathrm{~V}$ STATCOM and its performance is experimentally verified via state-of-the-art dSPACE DS1104.

\section{PROPOSED STATCOM WITH ANN/ANFIS CONTROLLERS}

Figure 1 shows the single line diagram of a power system with STATCOM. The STATCOM is connected at the middle of the transmission line. It consists of a VSC, a dc capacitor $\mathrm{C}_{\mathrm{dc}}$, shunt transformer, controller and a filter capacitor $\left(\mathrm{C}_{\mathrm{f}}\right)$. The VSC in STATCOM is modeled by connecting a 3 arm IGBT bridge. Each IGBT is antiparalleled by a diode. Sine triangular PWM technique is used to generate the AC sinusoidal output. The modulating signal is of $50 \mathrm{~Hz}$ sine wave and the carrier wave is of $20 \mathrm{KHz}$ triangular wave. The converter output is in PWM form. In order to bring it to sine waveform, an LC filter is connected to filter out the content of carrier wave having frequency of $20 \mathrm{KHz}$. The inductance of shunt transformer will act as $L$ for the LC filter.

dSPACE demonstrates high-end control development from block diagram design to on line controller optimization. It is possible to test even the most complex control systems in real time using dSPACE. It is possible to implement the simulink model of any system on dSPACE real time hardware within seconds and to observe the effects of parameter changes on system's behavior. dSPACE helps in varying the system parameters while doing the simulation there by the dynamic performance of the system can be easily observed. The DS1104 board that comes along with dSPACE consists of 8 ADCs and 8 DACs for interfacing.

The dSPACE layout of STATCOM model is created in SIMULINK environment. Then this model layout is converted into DSP code which runs in the in-built TMS320F240 DSP processor in the dSPACE controller. A dSPACE Connector panel (CLP1104) ports provide easy access to all input and output signals of the DS1104 board.

In the simulink model of STATCOM running under dSPACE environment it is not possible to generate a carrier wave of $20 \mathrm{KHz}$ since in dSPACE the simulation step size cannot be brought below $1 \mathrm{msec}$. In order to produce a sine triangular PWM for STATCOM a dedicated DSP TMS320F2407 is used. In that a sine wave of $50 \mathrm{~Hz}$ and 


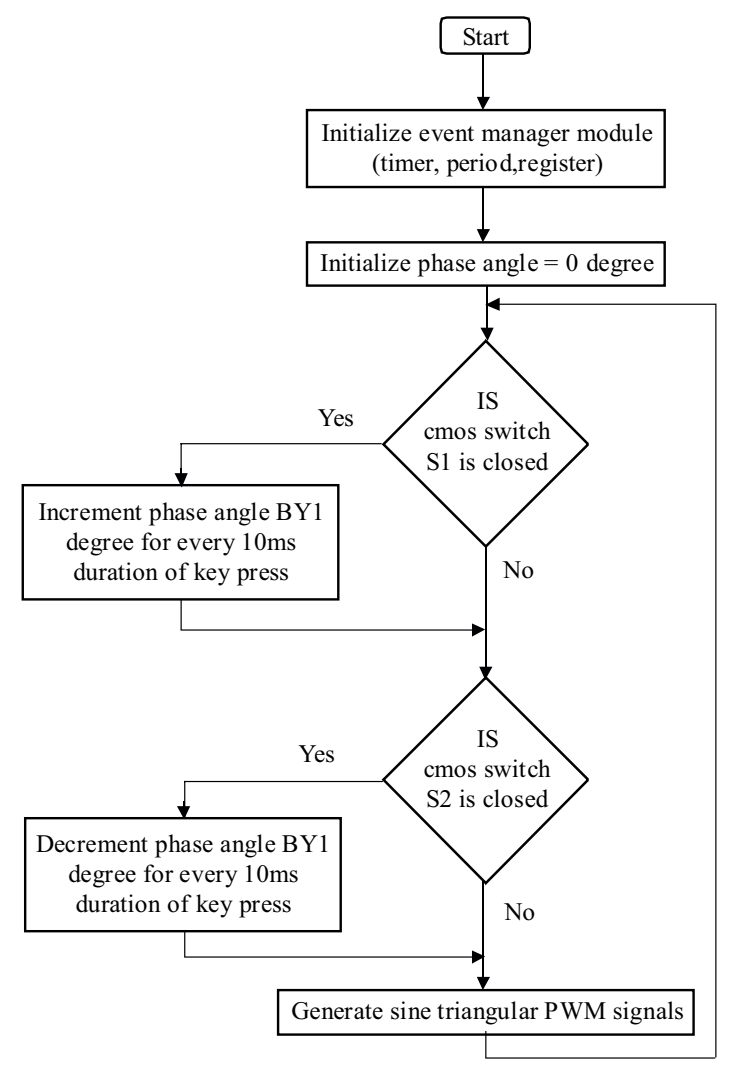

Fig. 3. Flow chart for the sine triangular PWM generation in DSP TMS320F 2407

carrier wave of $20 \mathrm{KHz}$ is compared and PWM is produced. A Phase Locked Loop(PLL) for synchronization with the bus voltage is used and a dead zone of 5 micro second is used in between the positive and negative group switching of IGBTs in VSC to avoid short circuit.

In order to vary the reactive power injected/absorbed by the STATCOM, the STATCOM injected voltage phase angle $\alpha$ is varied. To vary the phase angle, two CMOS switches (increment \& decrement) which are connected to two I/O pins of the DSP TMS320F240 are used. The signal on the I/O pin given through increment switch from dSPACE, is used to increment $\alpha$ and that of given through decrement switch is used to decrement $\alpha$. The modulation index is kept constant at 0.5 . Flow charts of Figs. 3 and 4 show this control phenomenon.

If the STATCOM has no power loss and operates to supply only reactive power, then no active power exchanges between the STATCOM and the ac system. Therefore, the inverter output voltage is controlled to be exactly in phase with the system voltage. The reactive power exchange between the STATCOM and the ac system can be controlled by varying the amplitude of the inverter output voltage. The switches of the inverter and passive components are not ideal and hence the dissipative power losses exist. The energy stored in the capacitor is eventually used to compensate internal losses of the converter. Hence the voltage across the capacitor cannot sustain and will eventually collapse. Therefore, a small amount of active power is required to compensate the dissipative power loss so that the dc capacitor voltage

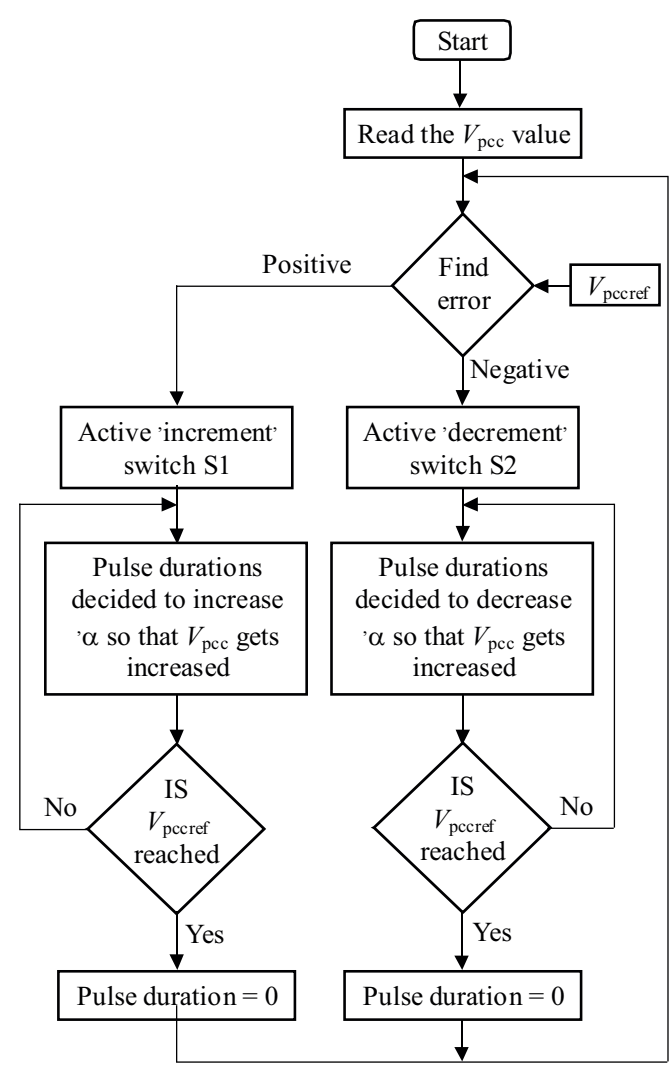

Fig. 4. Flow chart of control algorithm

can be maintained constant. This small amount of active power can be provided by the power system in such a way that there is a slight phase difference $(\alpha)$ between the system voltage and the STATCOM output voltage. This phase difference is achieved by adjusting the phase angle of the sinusoidal modulating signal. If the STATCOM's injecting current exceeds $10 \mathrm{~A}$ the PWM pulses will be cutoff in order to protect the VSC.

\section{MODELLING OF STATCOM}

The STATCOM is based on the principle that a voltage source inverter generates a controllable AC voltage source behind a transformer leakage reactance so that the voltage difference across the reactance produces active and reactive power exchange between the STATCOM and the transmission network. By injecting a current of variable magnitude in quadrature with the line voltage, the STATCOM can inject reactive power into the power system which is done by making the inverter output voltage greater than the bus voltage. At the same time it will absorb the reactive power from the power system when the inverter output voltage is less than the bus voltage. The STATCOM does not employ capacitor or reactor banks to produce reactive power as does the SVC, but instead uses a capacitor to maintain a constant dc voltage for the inverter operation.

The dc capacitor voltage can be adjusted by controlling the phase angle difference between line voltage and 
VSC voltage. The angle of line voltage is taken as reference. If the phase angles $\alpha$ is slightly advanced, beyond the system bus voltage the STATCOM injected voltage decreases and reactive power flows into STATCOM. Conversely, if the phase angle $\alpha$ is slightly delayed, the STATCOM injected voltage increases

Table 1. Details of the elements present in statcom

\begin{tabular}{ll}
\hline Source & 3 phase voltage source of $75 \mathrm{~V} /$ phase \\
Transmission line & $10+j 22.6 \Omega$ \\
STATCOM & $\pm 1 \mathrm{KVAR}$ \\
DC Capacitor $C_{\mathrm{dc}}$ & $20 \mu \mathrm{f}, 600 \mathrm{~V}$ \\
Filter capacitor $C_{\mathrm{f}}$ & $12.5 \mu \mathrm{f}, 440 \mathrm{~V}$ \\
Shunt transformer & 3 phase, $2.5 \mathrm{KVA}, 220 / 110 \mathrm{v}$ \\
Converter & 3 phase, $10 \mathrm{~A}$ IGBT converter \\
\hline
\end{tabular}

and STATCOM supplies reactive power to the bus. By controlling the phase angles of VSC, the reactive power can be generated from or absorbed by STATCOM and the voltage regulation can be achieved. The dc voltage maintained by the $\mathrm{C}_{\mathrm{dc}}$ will act as voltage source for the $\mathrm{VSC}$ and it is connected to the transmission line through a shunt transformer. Figure 2. shows the equivalent circuit of the STATCOM. The loop equations for the circuit may be written in vector form as

$$
\frac{\mathrm{d}}{\mathrm{d} t} i_{a b c}=-\frac{R_{s}}{L_{s}} i_{a b c}+\frac{1}{L_{s}}\left(E_{a b c}-V_{a b c}\right),
$$

where $R_{s}$ and $L_{s}$ represent the STATCOM transformer resistance and inductance respectively, $E_{a b c}$ are the inverter ac side phase voltages, $V_{a b c}$ are the system-side phase voltages, and $i_{a b c}$ are the phase currents. The output of the STATCOM is given by

$$
E_{a}=K V_{d c} \cos (\omega t+\alpha)
$$

where $V_{d c}$ is the voltage across the dc capacitor, $K$ is the modulation index, and $\alpha$ is the injected voltage phase angle. Table 1 gives the details of the elements present in the STATCOM and sample power system that is used in this network.

Figure 3 shows the flowchart for the sine triangular PWM generation in DSP TMS320F2407. At the starting of the program event manager module is initialized. The phase angle is set to zero and at the same time the modulation index value is made constant to 0.5 . The key press is done through Cmos switches S1 and S2. If switch $\mathrm{S} 1$ is closed then phase angle is increased by 1degree for every $10 \mathrm{msec}$ key press. If $\mathrm{S} 2$ is closed then phase angle is decreased by 1 degree for every $10 \mathrm{msec}$ of key press. According to the phase angle the sine triangular PWM is generated.

Figure 4 shows the flow chart of the control algorithm to control the phase angle $\alpha$.

\section{REAL TIME PERFORMANCE ANALYSIS OF STATCOM USING DSPACE DS1104 WITH ANN AND ANFIS CONTROLLERS}

\subsection{With ANNC}

In this section, the solution of implementing conventional PI controller in a neural network is discussed. The training patterns for ANNC are extracted from the conventional PI controller. The inputs, error(e), change in error(ce) and the outputs of PI controller are normalized to one and are taken as training data for the controller. The ANN controllers designed in most of the work use a complex network structure for the controller. The aim of this work is to design a simple ANN controller with number of neurons as low as possible while improving the performance of the controller. The command 'nntool' in the matlab/simulink is used to generate the neural network, based on the training data. A two layer feed forward neural network is constructed with two neurons in the input layer and one neuron in the output layer. Figure 6 shows the simulink diagram of the controller part of the power system of STATCOM with ANNC. As the inputs to the controller are the error and the change in error, two neurons are used for input layer. The maximum value of error and change in error before normalizing, are $150 \mathrm{v}$. The neurons are biased. The activation function used for the input and output neurons are pure linear and tangent sigmoid respectively. A supervised back propagation neural network-training algorithm is used with a ?xed error goal. The network is trained for an error goal of 0.0005 . The output from the ANNC is used to vary the phase angle $\alpha$. Figure 5 shows the structure of the neuron controller, where $W_{i j}$ represents the weight of the connections between neurons $i$ and $j$ and $b_{i}$ represents bias at neuron $i$. Figure 7 shows the simulink diagram of ANNC part of the STATCOM.

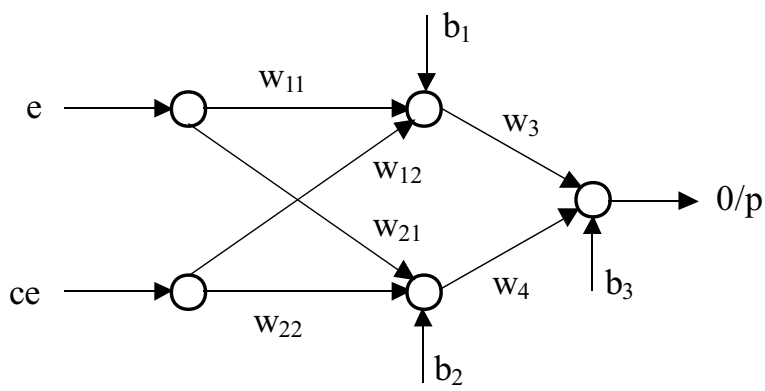

Fig. 5. Structure of the ANNC

\subsection{With ANFIS Controller}

In this section, the solution of implementing conventional PI controller in ANFIS is discussed. The training patterns for ANFIS are extracted from the conventional PI controller. The inputs, error(E), change in error(CE) and the outputs of PI controller are normalized to one and are taken as training and testing data for the controller. To take training data the 'to workspace' toolboxes for error(E), change in error(CE) and output(OP) are 


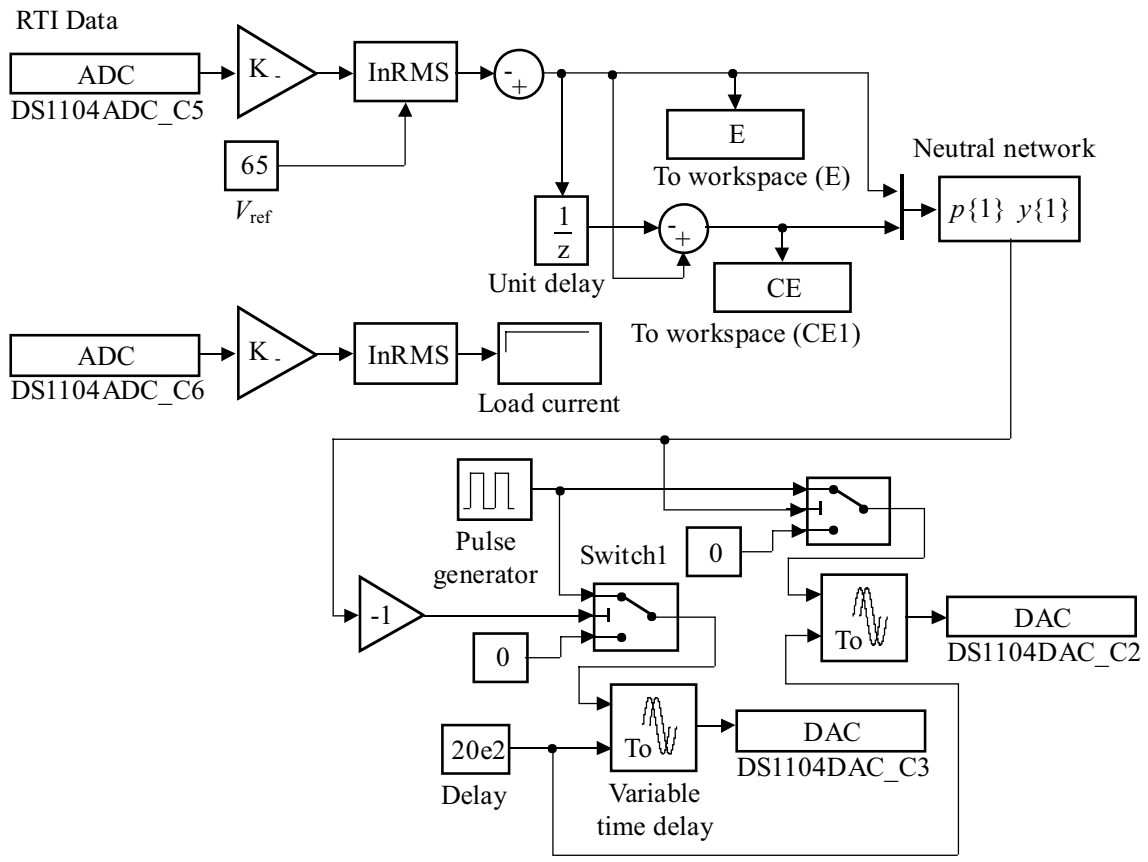

Fig. 6. Simulink diagram of the ANNC part of the STATCOM

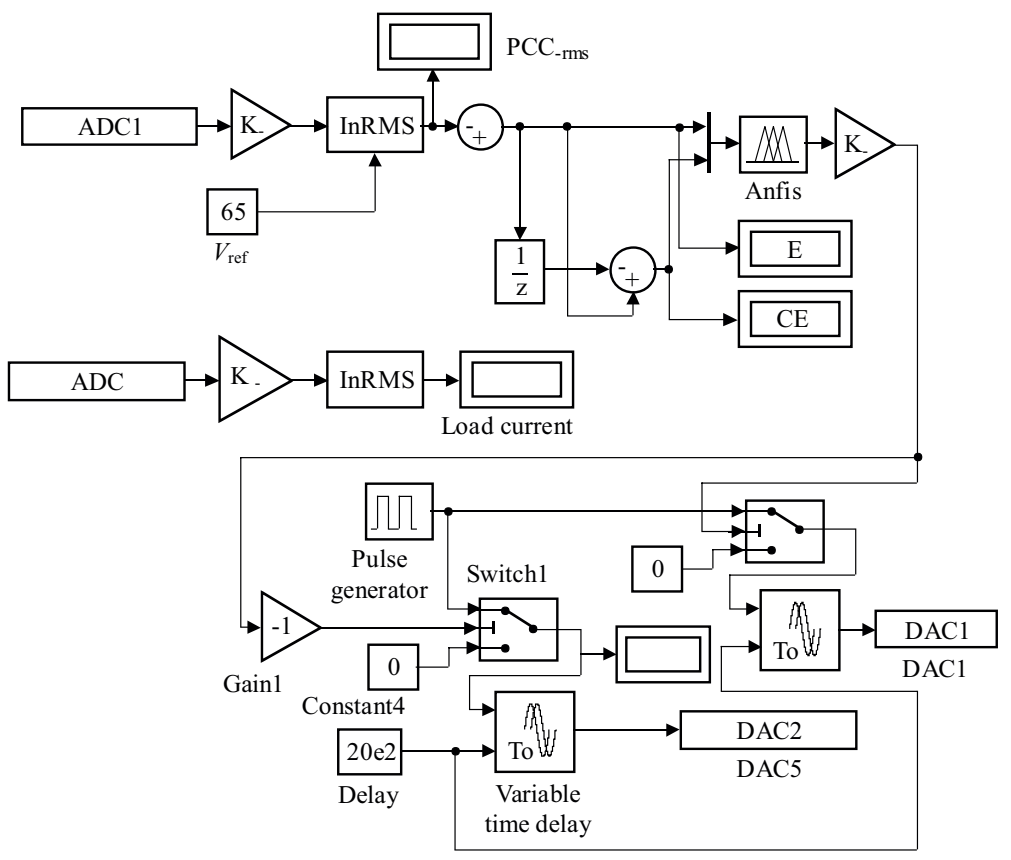

Fig. 7. Simulink diagram of the ANFIS controller part of the STATCOM

given by $0.1 \mathrm{~ms}$ sampling time. To take testing data the "to workspace' toolboxes for error(E1), change in error(CE1) and output(OP1) are given by $0.3 \mathrm{~ms}$ sampling time The ANFIS controllers designed in most of the work use a complex network structure for the controller. The aim of this work is to design a simple ANFIS controller and to improve the performance of this controller than the ANN controller.

In the input side 5 membership functions are used with triangular membership function Sugeno type fuzzy inference is used. Figure 7 shows the simulink diagram of the controller part of the power system of STATCOM with ANFIS.

The maximum value of error and change in error before normalizing, are $150 \mathrm{v}$. The network is trained for an error goal of 0.0005 . It takes 200 epochs to get that error goal. The output from the ANFIS is used to vary the phase angle $\alpha$. If the output form ANFIS is positive then the increment switch is activated and if the output is negative then the decrement switch is activated thereby changing the phase angle $\alpha$. Also if the magnitude of the ANFIS output is large, the corresponding switch is closed for a 
Table 2. Comparison of parameters when initial load disturbance is given (from $0.5 \mathrm{~A}$ to $1.1 \mathrm{~A}$ )

\begin{tabular}{lll}
\hline Parameters & ANN controller & ANFIS \\
\hline Peak overshoot & $22 \mathrm{~V}$ & $20 \mathrm{~V}$ \\
Settling time & $5 \mathrm{msec}$ & $3 \mathrm{msec}$ \\
Steady state error & $1.5 \mathrm{~V}$ & $1 \mathrm{~V}$ \\
\hline
\end{tabular}

Table 3. Comparison of parameters when final load disturbance is given (from $1.1 \mathrm{~A}$ to $0.5 \mathrm{~A}$ )

\begin{tabular}{lll}
\hline Parameters & ANN controller & ANFIS \\
\hline Peak overshoot & $50 \mathrm{~V}$ & $38 \mathrm{~V}$ \\
Settling time & $6 \mathrm{msec}$ & $3 \mathrm{msec}$ \\
Steady state error & $1.5 \mathrm{~V}$ & $1 \mathrm{~V}$ \\
\hline
\end{tabular}

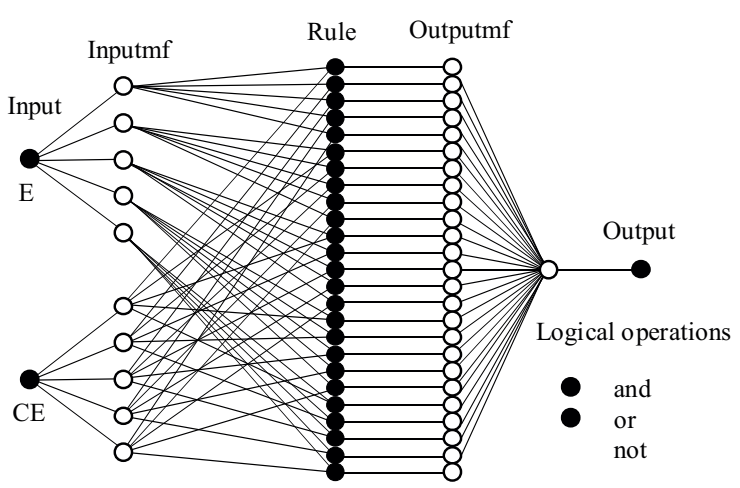

Fig. 8. Structure of the ANFIS

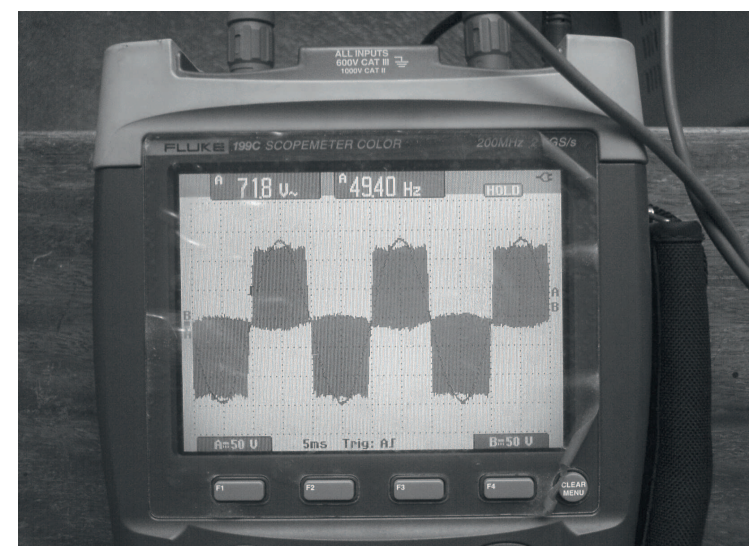

Fig. 9. STATCOM PWM and filtered sine wave output using dSPACE when connected with STATCOM and RL load

larger duration so as to change the phase angle $\alpha$ by a large amount and if it is small, then the corresponding switch is closed for a small duration. Figure 8 shows the model structure of the ANFIS controller.

\section{EXPERIMENTAL RESULTS AND ANALYSIS}

Figure 9 shows the STATCOM PWM output voltage and the filtered sine wave output voltage when connected with RL load.

\subsection{Result analysis with ANNC}

Figure 10 shows the change in the $V_{\mathrm{pcc}}$ voltage, error voltage and load current when ANN controller is connected. When the initial load disturbance (Load current from $0.5 \mathrm{~A}$ to $1.1 \mathrm{~A}$ ) is given the $V_{\text {pcc }}$ voltage is reduced to $48 \mathrm{v}$ and it takes 5 milliseconds (from 12 milliseconds to 17 milliseconds) to reach its steady state value of $70 \mathrm{v}$, and when the final load disturbance (Load current from $1.1 \mathrm{~A}$ to $0.5 \mathrm{~A}$ ) is given the $V_{\mathrm{pcc}}$ voltage is increased to $115 \mathrm{v}$ and it takes 6 milliseconds (from 31 millisecs to 37 millisecs) to reach its steady state value of $70 \mathrm{v}$. The steady state error is of $1.5 \mathrm{~V}$. Tables 2 and 3 give the comparison between the performances of the two controllers.

\subsection{Result Analysis With ANFIS Controller}

Figure 11 shows the change in the $V_{\mathrm{pcc}}$ voltage, error voltage and load current when ANFIS controller is connected. When the initial load disturbance (Load current from $0.5 \mathrm{~A}$ to $1.1 \mathrm{~A}$ ) is given the $V_{\mathrm{pcc}}$ voltage is reduced to $50 \mathrm{v}$ and it takes 3 milliseconds (from 8 milliseconds to 11 milliseconds) to reach its steady state value of $70 \mathrm{v}$, and when the final load disturbance (Load current from $1.1 \mathrm{~A}$ to $0.5 \mathrm{~A}$ ) is given the $V_{\mathrm{pcc}}$ voltage is increased to $108 \mathrm{v}$ and it takes 3 milliseconds (from 12 millisecs to 20 millisecs) to reach its steady state value of $70 \mathrm{v}$. The steady state error is of $1 \mathrm{~V}$. Tables 2 and 3 give the comparison between the performances of the two controllers.

\section{CONCLUSION}

This paper made an attempt to obtain the real time performance of STATCOM using both ANN and ANFIS controllers in dSPACE environment. The performance of STATCOM is analyzed by giving load disturbance. It is observed that the STATCOM under ANFIS controller is having less peak overshoot and steady state error It is also having faster response than ANN. Hence ANFIS controller is performing better than ANNC. Also it is found that using dSPACE, experimental verification of real time control system can be easily achieved

\section{Acknowledgement}

The authors wish to thank the management and Principal of Thiagarajar College of engineering for being constant source of encouragement. This work is supported in part by AICTE-RPS grant and DST-FIST scheme of Government of India.

\section{REFERENCES}

[1] HINGORANI, N. G.: Power Electronics in Electric Utilities: Role of Power Electronics in Future Power Systems, Proceedings of the IEEE Special Issue 76 No. 4, (Apr 1988), 481-482.

[2] HINGORANI, N. G.: Flexible AC Transmission Systems (FACTS) - Overview, IEEE Spectrum 30 No. 4 (Apr 1993), $40-45$. 


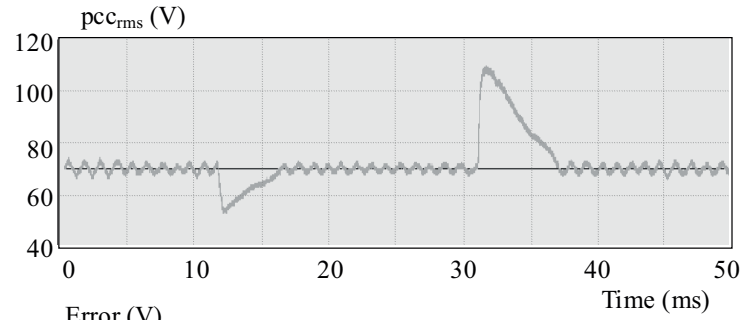

Error (V)

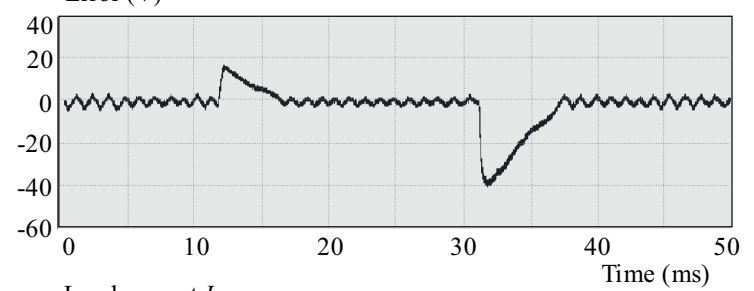

Load current $I_{\mathrm{n} 1}$

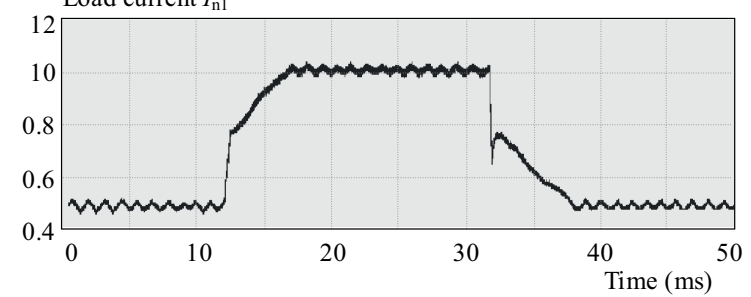

Fig. 10. Experiment results when load disturbance is given while using ANNC

[3] XU, L-AGELIDISV. G.-ACHA, E.: Development Considerations of DSP-Controlled PWM VSC-based STATCOM, IEE Proc-Electr. Power Appl. 148 No. 5 (Sep 2001), 449-455.

[4] SCHAUDER, C.-MEHTA, H.: Vector Analysis and Control of Advanced Static var Compensator, IEE Proceedings 140 (July 1993), 299-306.

[5] LEHN, P. W.-IRAVANI, M. R.: Experimental Evaluation of STATCOM in Closed loop Dynamics, IEEE Transactions on Power Delivery 13 No. 4 (Oct 1998), 1378-1384.

[6] VORAPHONPIPUT, N.-CHATRATANA, S.: STATCOM Analysis and Controller Design for Power System Voltage Regulation, IEEE/PES Transmission and Distribution Conference, China, 2005, pp. 1-6.

[7] LEHN, P. W. : Exact Modeling of the Voltage Source Converter, IEEE Transactions on Power Delivery vol17 No. 1 (Jan 2002), 217-222.

[8] DONG, L.-CROW, M. L.-YANG, Z.-SHEN, C.-ZHANG, L.-ATCITTY, S.: A Reconfigurable FACTS System for University Laboratories, IEEE transaction on Power systems 19 No. 1 (Feb 2004), 120-128.

[9] ZUNIGA-HARO, P.-RAMIREZ, J. M.: Multi-Pulse Switching Functions Modeling of Flexible AC Transmission Systems Devices, Electric Power Components and Systems 37 No. 1 (Jan 2009), 20-42.

[10] MAJUMDER, R.-PAL, B. C.-DUFOUR, C.-KORBA, P. : Design and Real-Time Implementation of Robust FACTS Controller for Damping Inter-Area Oscillation, IEEE Transactions on Power Systems 21 No. 2 pages809-816 (May 2006).

[11] DUFOUR, C.-BELANGER, J.: Real-Time Simulation of a 48-Pulse GTO STATCOM Compensated Power System on a Dual-Xeon PC using RT-LAB, International Conference on Power Systems Transients (IPST'05), Montreal, Canada P.No.IPST05, June 2005.

[12] XAVIER, S. A. E.-VENKATESH, P.-SARAVANAN, M.: Design of Intelligent Controllers for STATCOM, IEEE POWERCON 2008 New Delhi, Oct 2008, pp. 1-7.

[13] MOHAGHEGHI, S.-PARK, J.-W.-VENAYAGAMOORTHY, H. R. G.-CROW, G. K. : An Adaptive Neural
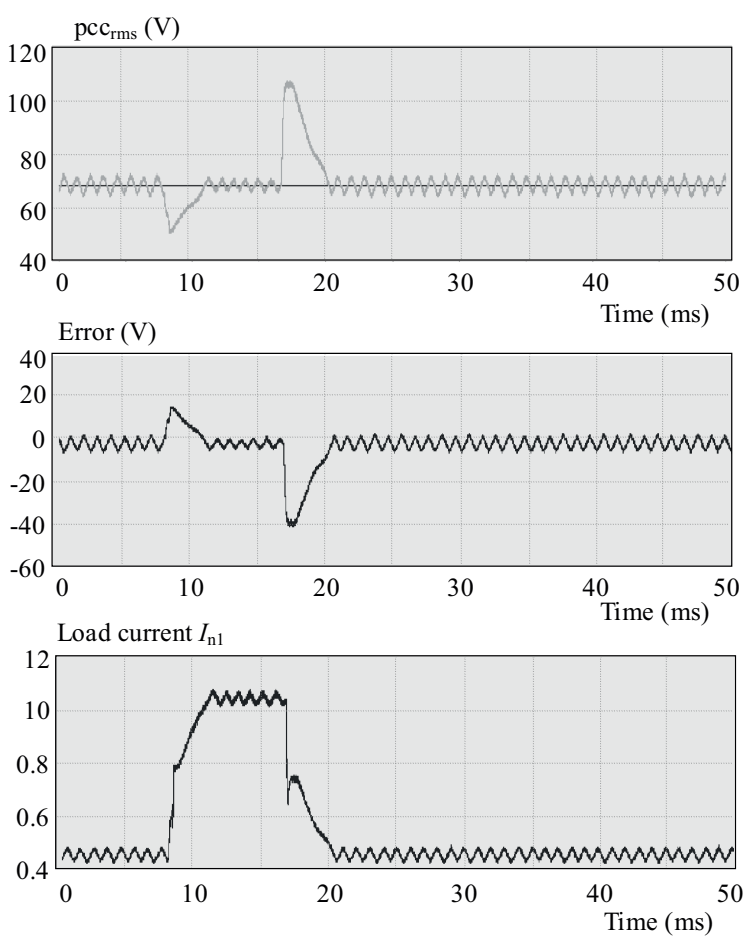

Fig. 11. Experiment results when load disturbance is given while using ANFIS controller

Network Identifier for Effective Control of a Static Compensator Connected to a Power System, Proceedings of the International Joint Conference on Neural Networks, vol. 4, 20-24 July 2003, pp. 2964-2969.

14] KIM, G. W.-LEE, K. Y.: Coordination Control of ULTC Transformer and STATCOM Based on an Artificial Neural Network, IEEE Transactions on power systems 20 (May 2005), $580-586$.

Received 29 July 2012

Santiago Arockia Edwin Xavier obtained BE, in Electrical and Electronics Engineering in the year 1998 and ME, in Power Electronics and Drives in 2005 from Anna University. Presently, he is a research scholar of Anna University, Chennai. He is persuing for $\mathrm{PhD}$, in the area of FACTS controllers. His special fields of interest include applications of power electronics in power systems and application of FACTS controllers to Power system areas.

Paramasivam Venkatesh received his Degree in Electrical and Electronics Engineering and Masters in Power System Engineering with Distinction and PhD in 1991, 1994 and 2003, respectively, from Madurai Kamaraj University, India. His area of interest is application of evolutionary computation techniques to power system problems and power system restructuring. He has received the Boyscast Fellowship award in the year 2006 from Department of Science and Technology, India for carrying out Post Doctoral Research Work at the Pennsylvania State University, USA He has to his credit more than sixteen papers published in repute journals.

Manimaran Saravanan received his Degree in Electrical and Electronics Engineering in 1991 and Masters in Applied Electronics in 1992 and $\mathrm{PhD}$ in 2007 from Madurai Kamaraj University, India. His area of interest is Power system and Power Electronics. His special fields of interest include application of PSO in power systems and application of FACTS controllers to power system areas. 